\title{
PENGARUH BUDAYA ORGANISASI, KOMITMEN ORGANISASI DAN KEPUASAN KERJA TERHADAP TURNOVER INTENTION PADA PT. SUKA FAJAR SOLOK
}

\author{
Desi Permata Sari, Sitti Rizki Mulyani, Darma Syahrullah Eka Jaya \\ Universitas Putra Indonesia YPTK Padang, Indonesia \\ Desipermatasari735@gmail.com
}

\begin{abstract}
ABSTRAK
Tujuan dari penelitian ini adalah untuk menganalisis pengaruh budaya organisasi, komitmen organisasi dan kepuasaan kerja terhadap turnover intention pada PT. Suka Fajar Solok. Sampel dalam penelitian ini adalah seluruh karyawan PT. Suka Fajar Solok. Data dalam penelitin ini diperoleh melalui kueioner. Hasil dari penelitian ini menunjukkan bahwa budaya organisasi mempunyai pengaruh negatif dan signifikan terhadap turnover intention, komitmen organisasi mempunyai pengaruh negatif dan signifikan terhadap turnover intention, kepuasaan kerja mempunyai pengaruh negatif dan signifikan terhadap turnover intention
\end{abstract}

Primary Key : Budaya Organisasi, Komitmen Organisasi, Kepuasaan Kerja dan Turnover Intention

\section{PENDAHULUAN}

Sumber Daya Manusia merupakan hal yang sangat penting dalam sebuah,organisasi karena tercapainya tujuan organisasi sangat bergantung pada kualitas dan kinerja individu yang ada.Sasaran dan tujuan yang telah ditetapkan tidak akan tercapai jika sumber daya manusia tidak memberikan sumbangan yang terhadap keberhasilan pencapain tujuan perusahaan. Oleh karena itu karyawan harus dipuaskan agar mereka termotivasi untuk melaksanakan pekerjaan sesuai dengan tugas yang diemban nya agar kinerja karyawan sesuai dengan yang diharapkan. Jika karyawan tidak puas mereka bisa pindah atau menarik diri atau keluar dari organisasi maka akan terjadi turnover

Menurut Mobley dalam (Hanafiah, 2014)Ada banyak faktor yang membuat individu memiliki keinginan untuk berpindah. Faktor-faktor tersebut diantaranya adalah budaya organisasi, kepuasan kerja, komitmen organisasi. Menurut (Wibowo, 2016) Budaya Organisasi merupakan pola kegitan manusia yang secara sistematis yang diturunkan dari generasi ke generasi melalui berbagai proses pembelajaran untuk menciptakan cara hidup tertentu yang paling cocok dengan lingkungan.

Budaya Organisasi menjadi penyebeb turnover karena karyawan tidak merasakan kecocokan dengan budaya dan lingkungan yang ada pada organisasi tersebut yang dapat menyebabkan tidak maksimalnya dalam bekerja dan menimbulkan rasa ingin meninggalkan organisasi untuk mendapatkan yang sesuai dengan keiinginan nya. Budaya Organisasi harus dibentuk, diterapkan, dan dikembangkan karena budaya organisasi merupakan pembentukan sifat, pola perilaku, dan nilai-nilai yang harus dipelajari, yang dimiliki semua anggota organisasi, dan diwariskan turun temurun dengan generasi berikutnya bukan terciptanya dengan sendirinya, melainkan dibentuk terlebih dahulu

Selaian budaya organisasi yang menjadi penyebab terjadinya turnover karyawan ada juga faktor nya adalah komitmen Organisasi. Komitmen organisasi mempengaruhi apakah pekerja akan tetap tinggal sebagai anggota organisasi atau meninggalkan organisasi dan mencari pekerjaan baru. 
Suatu komitmen organisasional menunjukkan suatu daya dari seseorang dalam mengidentifikasikan keterlibatannya dalam suatu bagian organisasi. Komitmen organisasional dibangun atas dasar kepercayaan pekerja atas nilai-nilai organisasi, kerelaan pekerja membantu mewujudkan tujuan organisasi dan loyalitas untuk tetap menjadi anggota organisasi, Oleh karena itu komitmen organisasional akan menimbulkan rasa ikut memiliki (sense of belonging) bagi pekerja terhadap organisasi,dan penyebab terjadinya turnover selanjutnya dalah Kepuasan Kerja

Menurut (Hasibuan, 2014) Kepuasan Kerja Adalah sikap emosional yang menyenangkan dan mencintai pekerjaaan nya, sikap ini dicerminkan oleh moral kerja, kedisiplinan dan prestasi kerja. Kepuasan kerja juga dapat menjadi penyebab terjadinya turnover karena karyawan yang tidak mendapatkan kepuasan kerja mereka menjadi sangat berkeinginan meninggalkan organisasi tersebut, kepuasan kerja karyawan dapat diwujudkan dengan pemberian gaji atau upah yang sesuai, promosi jabatan sehingga karyawan mendapatkan kepuasaan kerja dan tidak berfikir untuk meninggalkan organisasi atau perusahaan.

Kepuasan kerja merupakan hal yang bersifat individual karena setiap individu akan memiliki tingkat kepuasan yang berbeda-beda sesuai dengan nilai-nilai yang berlaku dalam diri mereka masing-masing. Karyawan akan menunjukkan komitmennya untuk tetap loyal ada perusahaan jika kepuasan kerja diperolehnya, sementara ketidakpuasan akan berpengaruh pada keluarnya pegawai.

PT. Suka Fajar Solok adalah distributor resmi kendaraan bermotor roda empat merek Mitsubisi yang bergerak dalam bidang memasarkan mobil, melayani dan memenuhi kebutuhan lainnya yang berhubungan dengan pemasaran merek Mitsubishi, seperti pusat perbengkelan dan penjualan suku cadang asli.

Dari hasil observasi awal yang dilakukan pada PT.Suka Fajar Solok data Turnover karyawan Terdapat pada tabel berikut

Tabel 1.1

Data Turnover Karyawan PT.Suka Fajar Solok Tahun 2015 Sampai 2017

\begin{tabular}{|c|c|c|c|c|c|}
\hline TAHUN & $\begin{array}{c}\text { JUMLAH } \\
\text { KARYAW } \\
\text { AN }\end{array}$ & $\begin{array}{c}\text { KARYAWAN } \\
\text { MASUK }\end{array}$ & PERSENTASE & $\begin{array}{c}\text { KARYAWAN } \\
\text { KELUAR }\end{array}$ & PERSENTASE \\
\hline 2015 & 74 & 13 & $9,62 \%$ & 12 & $8,88 \%$ \\
\hline 2016 & 78 & 14 & $10,92 \%$ & 10 & $7,8 \%$ \\
\hline 2017 & 76 & 13 & $9,12 \%$ & 8 & $6,08 \%$ \\
\hline
\end{tabular}

Sumber: Sumberdaya Manusaia PT.Suka Fajar Solok

Dari data diatas terlihat bahwa terjadi turnover intention pada PT.Suka Fajar Solok selama tiga tahun terakhir yaitu pada tahun 2015 Karyawan masuk sebanyak 13 sedangkan karyawan keluar sebanyak 12 orang, Sedangkan pada tahun 2016 terjadi perubahaan jumlah karyawan masuk ataupun keluar yaitu 14 karyawan masuk dan 10 karyawan yang keluar, dan pada tahun 2017 jumlah karyawan masuk berjumlah 13 dan 8 jumlah karyawan yang keluar. Angka turnover yang terjadi pada PT.Suka Fajar pasti memberikan dampak bagi perusahaan.

\section{TINJAUAN PUSTAKA}

\section{Turnover Intention}

Menurut (Dharma, 2013)Turnover Intention adalah derajat kecenderungan sikap yang dimiliki oleh karyawan untuk mencari pekerjaan baru di tempat lain atau adanya rencana untuk meninggalkan 
perusahaan dalam masa tiga bulan yang akan datang, enam bulan yang akan datang, satu tahun yang akan datang, dan dua tahun yang akan datang.

Menurut Mobley dalam (Hanafiah, 2014)Ada banyak faktor yang membuat individu memiliki keinginan untuk berpindah. Faktor-faktor tersebut diantaranya adalah kepuasan kerja, komitmen organisasi dari karyawan, kepercayaan terhadap organisasi, dan job insecuirity. Menurut Booth \& Hamer dalam (Hanafiah, 2014)Ada beberapa aspek yang dapat digunakan untuk melakukan pengukuran terhadap intention turnover yang terdiri dari tingkat komitmen, kepuasan kerja, dukungan managemen, perkembangan karir, dan peningkatan kerja. Menurut (Sidharta dan Margaret, 2011), ada dua jenis turnover berdasarkan fungsinya yaitu: FungsionalTurnover dan Disfungsional Turnover

\section{Budaya Organisasi}

Menurut (Wibowo, 2016) Budaya Organisasi merupakan pola kegitan manusia yang secara sistematis yang diturunkan dari generasi ke generasi melalui berbagai proses pembelajaran untuk menciptakan cara hidup tertentu yang paling cocok dengan lingkungan. Menurut (Stepen, 2008) Mendefinisikan budaya sebagai system makna bersama yang dianut oleh anggota-anggota yang membedakan organisasi itu dari organisasi - organisasi yang lain. Setiap organisasi memiliki budayanya sendiri, Budaya suatu organisasi mirip dengan kepribadian seseorang sebuah tema yang berwujud namun ada dan hadir menyertakan arti arahan serta dasar atas tindakan.

Menurut Robbins (2003) dalam (Mahyudi, 2017) Budaya Organisasi Merupakan sistem makna bersama terhadap nilai nilai primer yang dianut bersama dan dihargai organisasi, yang berbeda menciptakan pembedaan yang jelas antara suatu organisasi dengan organisasi lain nya, menciptakan rasa identitas bagi para anggota organisasi, mempermudah timbulnya komitmen kolektif terhadap organisasi, meningkatkan kemantapan sistemsosial, serta menciptakan mekanisme pembuatan makna kendali yang memadu membentuk sikap dan prilaku para anggota organisasi.

\section{Komitmen Organisasi}

Menurut Robbins (2003), Dalam (Suparyadi, 2015), mendefinisikan komitmen sebagai suatu keadaan dimana seorang individu memihak organisasi serta tujuan dan keinginannya untuk mempertahankan keanggotaanya didalam organisasi.

Menurut Marthis\&Jackson (2006) dalam (Suparyadi, 2015)Mendefinisikan Komitmen organisasi sebagai derejat dimana karyawan percaya dan mau menerima tujuan organisasi dan akan tetap atau tidak meninggalkan organisasi nya.

\section{Kepuasaan Kerja}

Menurut (Sunyoto, 2013)kepuasan kerja adalah keadaan emosional yang menyenangkan atau tidak meneyenangkan dimana karyawan memandang pekerjaan nya, Kepuasan kerja mencerminkan perasaan seseorang terhadap pekerjaan nya.

Menurut (Sumaryadi, 2015)kepuasan kerja adalah suatu sikap positif yang didasarkan pada hasil evaluasi terhadap apa yang diharapkan yang akan diperoleh melalui upaya-upaya yang dilakukan dalam melaksanakan suatu pekerjaan dengan hasil atau ganjaran yang diterima nya.

Menurut (Hasibuan, 2014)Kepuasan Kerja adalah sikap emosional yang menyenangkan dan mencintai pekerjaaan nya, sikap ini dicerminkan oleh moral kerja, kedisiplinan, dan prestasi kerja. Kepuasan kerja dinikmati dalam pekerjaan, luar pekerjaan dan kombinasi dalam dan luar pekerjaan. 
Menurut Robbins (2003) dalam (Wibowo, 2016), mendefinisikan kepuasan kerja sebagai sikap umum terhadap pekerjaan seseorang, yang menunjukkan perbedaan antara jumlah penghargaan yang diterima dan jumlah yang mereka yakin seharusnya mereka terima.

Kerangka pemikiran dalam penelitian ini disusun dalam bagan/skema kerangka berfikir sebagai berikut

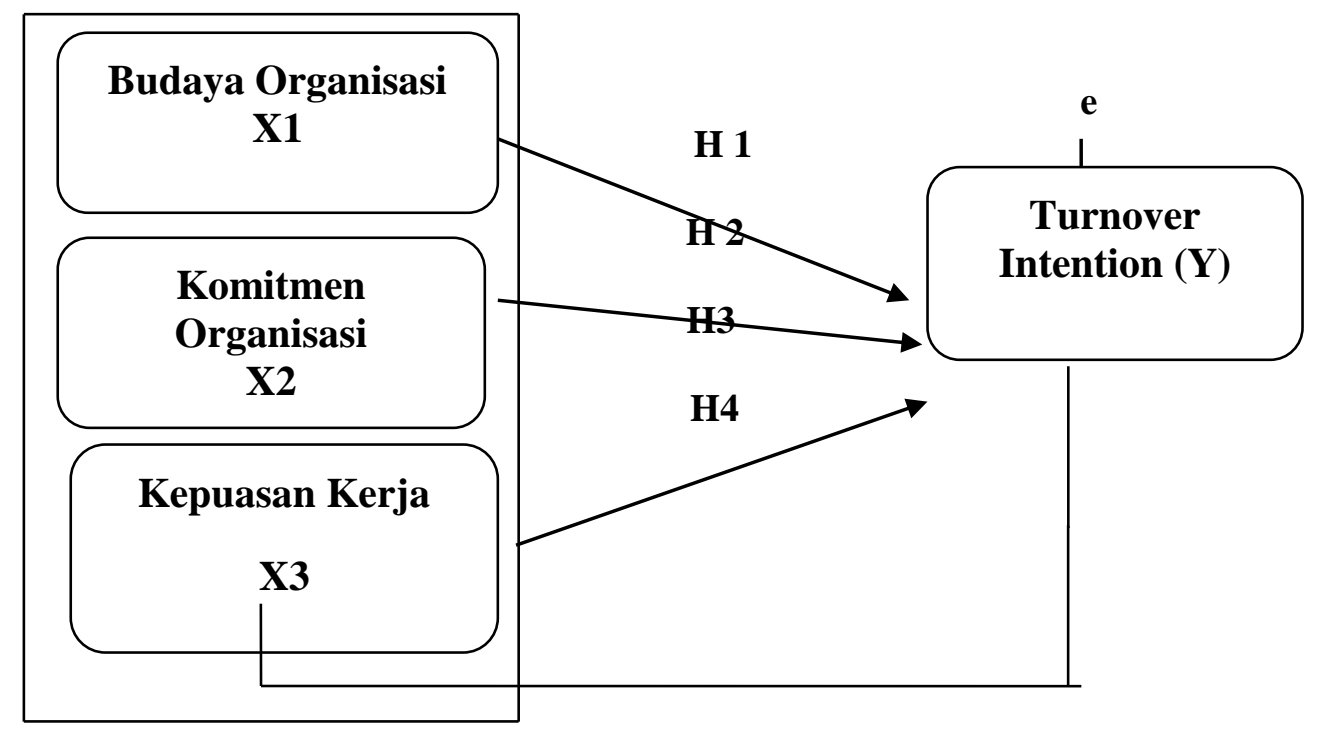

Gambar 2.1 Kerangka Pemikiran

\section{METODOLOGI PENELITIAN.}

\section{Uji validitas dan Reliabilitas Instrument Penelitian}

Pengujian ini dilakukan untuk mengukur sejauh mana tingkat validitas suatu kuesioner. Suatu alat ukur yang validitasnya tinggi akan mempunyai tingkat kesalahan kecil, sehingga data yang terkumpul merupakan data yang memadai. Validitas menunjukkan sejauh mana suatu alat ukur mampu mengukur apa yang ingin diukur (a valid measure if it succesfully measure the phenomenon).

Menurut (Sugiyono, 2014)Valid berarti instrumen tersebut dapat digunakan untuk mengukur apa yang seharusnya diukur.

Menurut (Ghozali, 2012)Uji Reliabilitas adalah alat untuk mengukur suatu kuesioner yang merupakan indikator dari variabel atau konstruk. Suatu kuesioner dikatakan reliabel atau handal jika jawaban seseorang terhadap pertanyaan adalah konsisten atau stabil dari waktu ke waktu.

\section{Teknis Analisis Data dan Uji Hipotesis}

\section{Statistik Deskriptif}

Statistik deskriptif memberikan gambaran mengenai karakteristik dari masing-masing variabel penelian, yang meliputi: mean, standar deviasi, nilai maksimum dan nilai minimum. 


\section{Uji Asumsi Klasik}

1. Uji Normalitas

2. Uji Multikolinearitas

3. Uji Heterokedastisiras

4. Uji autokorelasi

\section{Analisis Regresi}

Analisis regresi yang digunakan ialah analisis regresi berganda (Multiple Linear Regresion) yang akan diolah dengan menggunakan program SPSS 21.0.

\section{Uji Hipotesis}

Uji-t digunakan untuk menguji koefisien regresi secara parsial, dari variabel bebas terhadap variabel terikat. Dasar pengambilan keputusan adalah dengan membandingkan antara nilai probabilitas (p) dari t-hitung dengan taraf signifikansi $\alpha=5 \%$.

Uji-f digunakan untuk menguji seluruh variabel independen budaya organisasi, komitmen organisasi dan kepuasan kerja yang diteliti, mempunyai pengaruh secara bersama-sama terhadap variabel dependen turnover intention dilakukan dengan membandingkan $f_{\text {hitung }}$ dengan $f_{\text {tabel }}$.

\section{HASIL DAN PEMBAHASAN}

Analisis regresi tersebut menghasilkan koefisien-koefisien regresi yang menunjukkan arah hubungan sebab akibat antara variabel bebas dan variabel terikat. Hasil olahan data dengan bantuan SPSS 21.0 menggunakan model analisis regresi linear berganda dapat dilihat pada

Tabel 4.1

\section{Hasil Uji regresi Berganda}

Coefficients(a)

\begin{tabular}{|c|c|c|c|c|c|c|}
\hline \multicolumn{7}{|c|}{ Coefficients $^{\mathrm{a}}$} \\
\hline \multirow{2}{*}{\multicolumn{2}{|c|}{ Model }} & \multicolumn{2}{|c|}{$\begin{array}{l}\text { Unstandardized } \\
\text { Coefficients }\end{array}$} & \multirow{2}{*}{$\begin{array}{l}\text { Standardized } \\
\text { Coefficients } \\
\text { Beta }\end{array}$} & \multirow[b]{2}{*}{$\mathrm{t}$} & \multirow[b]{2}{*}{ Sig. } \\
\hline & & $\mathrm{B}$ & Std. Error & & & \\
\hline \multirow[t]{4}{*}{1} & (Constant) & 47,899 & 2,870 & & 16,688 &, 000 \\
\hline & Budaya Organisasi &,- 443 & 065 &,- 497 & $-6,851$ & 000 \\
\hline & $\begin{array}{l}\text { Komitmen } \\
\text { Organisasi }\end{array}$ &,- 277 & ,061 &,- 331 & $-4,500$ &, 000 \\
\hline & Kepuasan Kerja &,- 276 & ,065 &,- 304 & $-4,256$ &, 000 \\
\hline
\end{tabular}

Berdasarkan perhitungan melalui komputer dengan menggunakan program SPSS 21.0 dapat diketahui nilai konstanta sebesar 47,899 nilai koefisiensi regresi $\beta 1$-,443 koefisiensi regresi $\beta 2-, 277$, nilai koefisiensi regresi $\beta 3-, 276$. 


\section{Uji t (t-test)}

\section{Hasil Uji Pengaruh Budaya Organisasi Terhadap Turnover Intention}

Diperoleh nilai t hitung $<\mathrm{t}$ table $(-6,851<1,994)$ dengan tingkat siginifikan $(0,000<0,05)$, berarti Ho ditolak Ha diterima. Dengan demikian dapat dikatakan terdapat pengaruh negatif dan signifikan antara Budaya Organisasi dengan Turnover Intetion Karyawan PT. Suka Fajar Solok.

Hasil Penelitian ini sejalan dengan penelitian yang dilakukan oleh (Widayati, 2016) Budaya Organisasi berpengaruh negatif dan signifikan terhadap Turnover Intetion.

\section{Hasil Uji Komitmen Organisasi Terhadap Turnover Intention}

Diperoleh nilai t hitung $<\mathrm{t}$ table $(-4,500<1,994)$ dengan tingkat siginifikan $(0,000<0,05)$, berarti Ho ditolak Ha diterima. Dengan demikian dapat dikatakan terdapat pengaruh negatif dan signifikan antara Komitmen Organisasi dengan Turnover Intetion Karyawan PT. Suka Fajar Solok.

Hasil Penelitian ini sejalan dengan penelitian yang dilakukan oleh (Yoga, 2016) bahwa komitmen organisasi memiliki pengaruh negatif dan signifikan terhadap turnover intetion.

\section{Hasil Uji Kepuasaan Kerja Terhadap Turnover Intention}

Diperoleh nilai t hitung $<\mathrm{t}$ table $(-4,256<1,994)$ dengan tingkat siginifikan $(0,000<0,05)$, berarti Ho ditolak Ha diterima. Dengan demikian dapat dikatakan terdapat pengaruh negatif dan signifikan antara Kepuasan Kerja dengan Turnover Intetion Karyawan PT. Suka Fajar Solok.

Hasil Penelitian ini sejalan dengan penelitian yang dilakukan oleh (Pawesti \& Wikansari, 2016) menunjukkan bahwa secara parsial kepuasan kerja berpengaruh signifikan negatif terhadap turnover intention.

\section{Tabel 4.2}

\section{Hasil Uji regresi Berganda}

anova

\begin{tabular}{|c|c|c|c|c|c|c|}
\hline \multicolumn{7}{|c|}{ ANOVA $^{\text {a }}$} \\
\hline \multicolumn{2}{|c|}{ Model } & $\begin{array}{ll}\text { Sum } & \text { of } \\
\text { Squares } & \end{array}$ & Df & Mean Square & $\mathrm{F}$ & Sig. \\
\hline \multirow[t]{3}{*}{1} & Regression & 378,847 & 3 & 126,282 & 49,105 &, $000^{\mathrm{b}}$ \\
\hline & Residual & 180,018 & 70 & 2,572 & & \\
\hline & Total & 558,865 & 73 & & & \\
\hline
\end{tabular}

Dibuktikan nilai $\mathrm{Fa}_{\text {hitung }} 49,105>\mathrm{F}_{\text {tabel }} 2,736$ dengan tingkat siginifikan $(0,000<0,05)$. berarti Ho ditolak Ha diterima. Dengan demikian dapat dikatakan terdapat pengaruh dan signifikan terdap antara Budaya Organisasi, Komitmen Organisasi, dan Kepuasan Kerja Turnover Intetion Karyawan PT. Suka Fajar Solok. Serta diperoleh angka Adjusted $R$ square $\left(\mathrm{R}^{2}\right)$ sebesar 0,664 atau $66 \%$, hal ini menunjukkan bahwa persentase sumbangan variabel indepen Budaya Organisasi $\left(\mathrm{X}_{1}\right)$, Komitmen Organisasi $\left(\mathrm{X}_{2}\right)$, Kepuasan Kerja $\left(\mathrm{X}_{3}\right)$ terhadap variabel dependen Turnover Intention $(\mathrm{Y})$ sebesar 0,678 atau $66 \%$, Sedangkan sisanya sebesar 34\% dipengaruhi oleh variabel lain di luar penelitian ini. 
Jurnal EKOBISTEK Fakultas Ekonomi, Vol.8, No. 1, April 2019, Hal 117-123 ISST: 2301-5268 | E-ISSN: 2527-9483 Copyright@2018 by LPPM UPI YPTK Padang

\section{KESIMPULAN}

Berdasarkan analisa data, interpretasi hasil penelitian, dan pembahasan yang telah disampaikan sebelumnya, maka dapat dikemukakan beberapa kesimpulan dari hasil penelitian ini sebagai berikut:

1. Budaya Organisasi berpengaruh negatif dan signifikan terhadap Turnover Intention Karyawan pada PT. Suka Fajar Solok, diperoleh dari nilai $t_{\text {hitung }}>t_{\text {tabel }}$ (lihat pada tabel 4.1 Hasil Uji $t$ )

2. Komitmen Organisasi terhadap berpengaruh negatif dan signifikan terhadap Turnover Intention Karyawan pada PT. Suka Fajar Solok, diperoleh dari nilai $t_{\text {hitung }}>t_{\text {tabel }}$ (lihat pada tabel 4.1 Hasil Uji t)

3. Kepuasan Kerja berpengaruh nefatif dan signifikan terhadap Turnover Intention Karyawan pada PT. Suka Fajar Solok, diperoleh dari nilai $t_{\text {hitung }}>t_{\text {tabel }}$ (lihat pada tabel 4.1 Hasil Uji $t$ )

4. Terhadapat pengaruh Budaya Organisasi, Komitmen Organisasi, dan Kepuasan Kerja secara bersama-sama berpengaruh terhadap Turnover Intentionkaryawan PT. Suka Fajar Solok. Berdasarkan hasil perhitungan statistik menunjukkan hasil nilai $F_{\text {hitung }}>F_{\text {tabel }} F_{\text {hitung }} 49,105$ $>\mathrm{F}_{\text {tabel }} 2,736$ dengan tingkat siginifikan $(0,000<0,05)$. Dengan demikian dapat dikatakan terdapat pengaruh negatif dan signifikan terdap antara Budaya Organisasi, Komitmen Organisasi, dan Kepuasan Kerja terhadapTurnover Intetion Karyawan PT. Suka Fajar Solok. Serta diperoleh angka Adjusted $R$ square $\left(\mathrm{R}^{2}\right)$ sebesar 0,664 atau $66 \%$, hal ini menunjukkan bahwa persentase sumbangan variabel indepen Budaya Organisasi $\left(\mathrm{X}_{1}\right)$, Komitmen Organisasi $\left(\mathrm{X}_{2}\right)$, Kepuasan Kerja $\left(\mathrm{X}_{3}\right)$ terhadap variabel dependen Turnover Intention $(\mathrm{Y})$ sebesar 0,678 atau $66 \%$, Sedangkan sisanya sebesar $34 \%$ dipengaruhi oleh variabel lain di luar penelitian ini.

\section{Daftar Pustaka}

1. Dharma, S. (2013). Manajemen Kinerja : Falsafah, Teori dan Penerapannya. yogyakarta.

2. Ghozali, I. (2012). Aplikasi Analisis Multivariat Dengan Program IBM SPSS 20. semarang.

3. Hanafiah, M. (2014). Pengaruh Kepuasan Kerja dan Ketikamanan Kerja ( Job Insecuryty ) Dengan Intensi Pindah Kerja( Turnover ) Pada Karyawan PT . Buma Desa Suaran Kecamatan Sambaliung, 1(3), 303-312.

4. Hasibuan, M. (2014). Manajemen Sumber Daya. jakarta.

5. Mahyudi, D. (2017). Pengaruh Budaya Organisasi dan Motivasi Kerja Terhadap Kepuasan Kerja Dan Loyalitas Bagian Kantor pada PT. Ramajaya Pramukti Kabupaten Kampar, 750763.

6. Pawesti, R., \& Wikansari, R. (2016). Pengaruh Kepuasan Kerja Terhadap Intensi.

7. Sidharta dan Margaret, M. (2011). Komitmen Organisasi Terhadap Kepuasan Kerja.Pdf.

8. Stepen, p robin. (2008). Perilaku Organisasi.

9. Sugiyono. (2014). Metode Penelitian Pendidikan Pendekatan Kuantitatif, K ualitatif dan $R \& D$. bandung.

10. Sumaryadi, I. nyoman. (2015). Perencanaan Pembangunan Daerah Otonom dan Pemberdayaan Masyarakat. (C. Utma, Ed.). jakarta.

11. Sunyoto, D. (2013). Metodologi Penelitian Akuntansi. (P. R. A. A. IKAPI, Ed.). Bandung.

12. Suparyadi. (2015). Manajemen Sumber Daya Manusia, Menciptakan Keunggulan Bersaing Berbasis Kompetisi SDM. Jakarta.

13. Wibowo. (2016). Manajemen Kinerja Edisi ke Empat, Rajawali. JAKARTA.

14. Widayati, C. (2016). Pengaruh Kompensasi dan Budaya Organisasi Terhadap Turnover Intention, $X X(03), 387-401$.

15. Yoga, W. (2016). Pengaruh Komitmen Organisasi dan Kepuasaan Kerja Terhadap Turnover Intention, 468-480. 